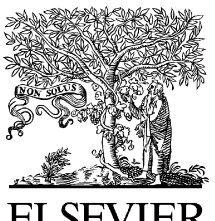

\title{
European first aid guidelines
}

\author{
Stijn Van de Velde*, Paul Broos, Marc Van Bouwelen, Rudy De Win, \\ An Sermon, Johann Verduyckt, André Van Tichelen, Door Lauwaert, \\ Barbara Vantroyen, Christina Tobback, Patrick Van den Steene, \\ Sarmite Villere, Carlos Urkia Mieres, Gabor Göbl, Susanne Schunder, \\ Koenraad Monsieurs, Joost Bierens, Pascal Cassan, Enrico Davoli, \\ Marc Sabbe, Grace Lo, Maaike De Vries, Bert Aertgeerts,
}

\section{on behalf of the European First Aid Manual project by the Belgian Red Cross-Flanders}

Training Department, Belgian Red Cross-Flanders, Motstraat 40, 2800 Mechelen, Belgium

Received 26 August 2006; received in revised form 20 October 2006; accepted 20 October 2006

KEYWORDS
Emergency treatment;
Evidence-based
medicine;
First aid;
Guidelines;
Training

KEYWORDS

Emergency treatment;

medicine;

Guidelines;

Training

\begin{abstract}
Summary
Aim: Our objectives were to determine the most effective, safe, and feasible first aid (FA) techniques and procedures, and to formulate valid recommendations for training. We focussed on emergencies involving few casualties, where emergency medical services or healthcare professionals are not immediately present at the scene, but are available within a short space of time. Due to time and resource constraints, we limited ourselves to safety, emergency removal, psychosocial FA, traumatology, and poisoning. Cardiopulmonary resuscitation (CPR) was not included because guidelines are already available from the European Resuscitation Council (ERC). The FA guidelines are intended to provide guidance to authors of FA handbooks and those responsible for FA programmes. These guidelines, together with the ERC resuscitation guidelines, will be integrated into a European FA Reference Guide and a European FA Manual.
\end{abstract}

\footnotetext{
A Spanish translated version of the summary of this article appears as Appendix in the final online version at ...

Guidelines are not a substitute for the caregiver's own judgment of a specific medical or health condition. Casualties should consult a qualified health-care professional for advice about a specific condition. The authors disclaim any liability to any party for any damages arising out of the use or non-use of this material and any information contained therein, and all warranties, expressed or implied.

* Corresponding author. Tel.: +32 15443476.

E-mail address: stijn.vandevelde@rodekruis.be (S. Van de Velde).
} 
Methods: To create these guidelines we used an evidence-based guideline development process, based on the methodology of the Scottish Intercollegiate Guidelines Network (SIGN).

Results: The recommendations cover FA for bleeding, wounds, burns, spinal and head trauma, musculoskeletal trauma, and poisoning, as well as safety and psychosocial FA. Conclusions: Where good evidence was available, we were able to turn science into practice. Where evidence was lacking, the recommendations were consensus-based. These guidelines provide systematically developed recommendations and justifications for the procedures and techniques that should be included in FA manuals and training programmes.

(c) 2006 Published by Elsevier Ireland Ltd.

\section{Introduction}

Every year, thousands of people experience or witness medical emergencies. When emergencies occur, family members, friends, colleagues, or bystanders often provide spontaneous help. ${ }^{1-3}$ Citizens can take safety precautions and help others until professional help arrives. First aid (FA) training is essential in preparing the general public for an initial response to such situations.

To improve the outcome of the casualty, first aiders must be taught correctly; they must be given training in the right things. Incorrect training can result in inadequate, even harmful, interventions. The procedures and techniques taught to the public vary between European countries, but these differences cannot always be justified. Recently, the American Heart Association published guidelines for resuscitation and $\mathrm{FA},{ }^{4}$ the European guidelines that were published at the same time only covered resuscitation. ${ }^{5}$ European FA guidelines, which incorporate research and expert opinion systematically and transparently, therefore are much needed.

Belgian Red Cross-Flanders initiated a project to determine the most effective, safe, and feasible FA techniques and procedures, and to formulate valid recommendations. This project received support from the European Commission. The guidelines cover emergencies involving few casualties, where emergency medical services (EMS) or healthcare professionals are not present at the scene immediately, but are available within a short space of time. Due to time and resource constraints, we limited ourselves to safety, emergency removal, psychosocial FA, traumatology, and poisoning. Cardiopulmonary resuscitation (CPR) is not included, because guidelines ${ }^{5}$ are already available from the European Resuscitation Council (ERC).

We define FA as 'immediate help provided to a sick or injured person'. FA consists of procedures and techniques, requiring minimal or no equip- ment, that can be taught to the general public in basic FA courses. FA is not only concerned with the treatment of physical injury but also with providing other initial care to the individual, including psychosocial FA-assistance given to people suffering emotional distress caused by experiencing or witnessing a stressful event. A first aider is defined as a layperson trained in FA.

These guidelines have been designed to provide guidance to authors of FA handbooks and those responsible for FA programmes. They are intended to be a blueprint for local training programmes and to increase the usefulness, quality, impact, and harmonisation of training. This will improve both the quality of FA provided and the outcome for the casualty.

Together with the resuscitation guidelines of the ERC, these guidelines will be bundled into the European Reference Guide for FA Instruction. This Reference Guide should be a helpful tool for the dissemination of the guidelines throughout Europe. To implement the new guidelines simply and efficiently across Europe, we produced EFAM or European FA Manual. EFAM collates all the new guidelines for first aid and resuscitation into one unique tool to update teaching material. It offers ready-to-use digital texts and high quality photos of all the latest techniques. The Reference Guide and EFAM can be requested from the European First Aid Manual website http://www.efam.be.

\section{Methodology}

The guideline development process was based on the methodology of the Scottish Intercollegiate Guidelines Network (SIGN). ${ }^{6}$ This is a recognised reference for the development of guidelines. ${ }^{7}$

\section{Guideline Development Group}

When composing the Guideline Development Group, we ensured participation from all relevant 
key groups and disciplines. The group consisted of European specialists in anaesthesiology, cardiology, traumatology, emergency medicine, disaster management, psychosocial care, medical education, and FA training. The director of the Belgian branch of the Cochrane Collaboration, i.e. the Belgian Centre for Evidence-Based Medicine (CEBAM), gave advice on methodology. The experts who conducted the systematic literature review participated in training in evidence-based medicine.

\section{Literature search and data sources}

The objective of the search was to find all relevant studies using sensitive search strategies. An initial search was performed for guidelines and systematic reviews (SR) in the Cochrane Database of Systematic Reviews, the Guidelines International Network database, the Health Evidence Network, the National Guideline Clearinghouse, the National Electronic Library for Health Guidelines Finder, and Pubmed. A subsequent search for other studies was carried out using Pubmed, Embase, and the Web of Science. Where eligible guidelines or SRs were found, the subsequent search focussed on studies published thereafter, up to December 2005. Hand searching and checking the reference lists of selected studies enabled the inclusion of studies that were not retrieved in the initial search. The detailed search strategy is available upon request.

\section{Selection of studies}

Inclusion and exclusion criteria were defined before the selection procedure. There were no language restrictions or limits on study design. Studies were selected from the titles and abstracts of all the retrieved references. Full texts were then screened and irrelevant studies were excluded.

\section{Quality assessment}

All the selected studies were evaluated for methodological quality using checklists. We used the AGREE instrument ${ }^{8}$ from the AGREE Collaboration for assessing guidelines, and the SIGN checklist for reviewing SRs, randomised controlled trials (RCT), and cohort and case-control studies. We developed additional checklists for other study designs.

\section{Data extraction}

The data from valid studies were tabulated in evidence tables and summarized by level of evidence. Evidence statements and recommendations were formulated at a conference held in Riga, Latvia, in February 2006. If no relevant research evidence was found, recommendations were based on a consensus of what was considered good practice. For each recommended FA technique or procedure, we assessed the effectiveness, safety, and feasibility. In accordance with the SIGN grading system ${ }^{6}$ (Figure 1), our recommendations are graded from $A$ to $D$. These grades match the strength of the supporting evidence, ranging from LOE 1 to 4 . Where evidence was unavailable, the recommendation is based on a consensus of the Guideline Development Group as to what constitutes good practice.

\section{Validation}

External reviewers, including medical specialists, experts in psychosocial care, training managers, and trainers, made an initial assessment of each guideline statement. They gave feedback on scope, quality, clarity, and usefulness. The Guideline Development Group then considered the responses. An independent expert committee, following the CEBAM external validation procedure, officially validated the final guidelines.

\section{Evidence}

Table 1 shows the number of studies identified, included, and excluded. In total we selected 88 studies to support our recommendations. The American FA guidelines ${ }^{4}$ were included under multiple topics, thus explaining why 'total included' in Table 1 amounts to 93 rather than 88 .

We included 23 guidelines, 5 SRs, 2 RCTs, 1 cohort study, 14 case reports or series, 2 cross-sectional surveys, and 41 miscellaneous manuscripts (narrative reviews, letters, comments, etc.). Five guidelines contained specific recommendations for FA. ${ }^{4,9-12}$ The other guidelines were for use by healthcare professionals, but extrapolation to FA recommendations was possible. Twelve guidelines ${ }^{4,10,12-21}$ used systematic and transparent methods for integrating research evidence, two guidelines ${ }^{9,11}$ were based on expert consensus, and for nine guidelines $22-30$ we could not retrace what method was used. Eight guidelines included grades of recommendation. When appropriate guidelines or SRs were found, we focussed the subsequent search on later publications, up to December 2005. This was the case for psychosocial FA, wounds, burns, spinal and head trauma, musculoskeletal trauma, and poisoning. 


\section{Levels of evidence}

1++ High quality meta analyses, SRs of RCTs, or RCTs with a very low risk of bias

1+ Well conducted meta analyses, SRs of RCTs, or RCTs with a low risk of bias

1- Meta analyses, SRs or RCTs, or RCTs with a high risk of bias

2++ High quality SRs of case control or cohort studies or High quality case control or cohort studies with a very

low risk of confounding, bias, or chance and a high probability that the relationship is causal

$2+$ Well conducted case control or cohort studies with a low risk of confounding, bias, or chance and a moderate

probability that the relationship is causal

2- Case control or cohort studies with a high risk of confounding, bias, or chance and a significant risk that the

relationship is not causal

3 Non analytic studies, e.g. case reports, case series

4 Expert opinion

\section{Grades of recommendations}

A At least one meta analysis, SR, or RCT rated as $1++$ and directly applicable to the target population or A SR of RCTs or a body of evidence consisting principally of studies rated as $1+$ directly applicable to the target population and demonstrating overall consistency of results

B A body of evidence including studies rated as $2++$ directly applicable to the target population and demonstrating overall consistency of results or Extrapolated evidence from studies rated as $1++$ or $1+$ C A body of evidence including studies rated as 2 + directly applicable to the target population and demonstrating overall consistency of results or Extrapolated evidence from studies rated as $2++$

D Evidence level 3 or 4 or Extrapolated evidence from studies rated as $2+$

Figure 1 SIGN grading system. ${ }^{6}$

\section{Safety measures}

\section{Findings}

We included eight studies on road accidents, ${ }^{31-38}$ two on fire, ${ }^{39,40}$ and seven on electrical accidents. ${ }^{40-46}$ Except for one cross-sectional survey on fire safety (LOE $\left.3^{39}\right)$, all the selected studies on safety measures are expert opinion documents (LOE 4). As to road accidents, there is debate among specialists whether parking the car before or after the accident is important.

\section{Recommendations (Grade D)}

\section{General principles}

Always make personal safety your first priority. Check the situation and identify any potential dan- ger. Only approach the scene if it is safe for you to do so. If possible, try to ensure safety for the casualty and bystanders. If it is unsafe for you to approach the casualty, alert the emergency services and wait at a safe distance for their arrival.

\section{Road accident}

Always act according to local laws.

When approaching a road accident, reduce speed and avoid sudden braking. Park your car in a safe place, off the road or at the side of the road. Wear high visibility clothing. Use warning signs (e.g. warning triangle) to alert passing traffic. Do not run across busy travel lanes on motorways.

Identify any downed electrical cables and ensure that nobody touches or approaches them. 


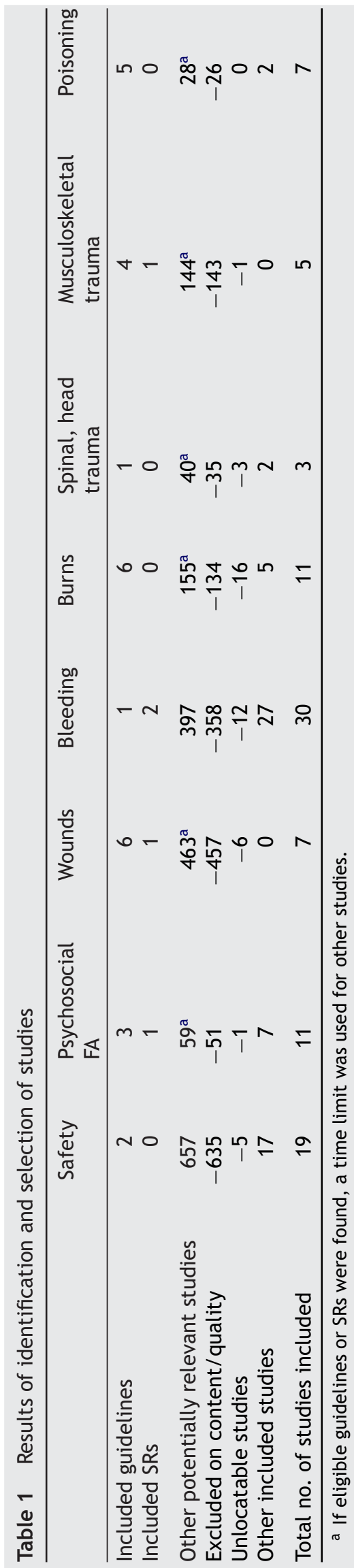

Prevent fire by switching off the ignition of vehicles involved in the accident, and ensuring that nobody smokes. Be aware of the danger of airbags. If possible, apply the handbrake to stabilise the vehicles involved.

\section{Fire at home}

Try to warn everybody at risk without putting yourself at risk. Do not enter a burning house. Move away from the area to a safe distance. If you are in a burning building, leave the area immediately and help other people to leave, provided you can do this safely.

\section{Electrical accident at home}

Consider electrical devices and cables as 'live' until proven to be disconnected. Do not touch a casualty connected to a power source. Remember that liquids or objects in contact with the casualty can potentially conduct electricity. Switch off the current. If it is not possible to disconnect the power, stand on insulating material and push the power source away using nonconductive material. If this is not feasible, wait for the fire brigade or specialised personnel to arrive.

\section{Emergency removal of the casualty}

\section{Findings}

Three expert opinion manuscripts are included on emergency removal of the casualty (LOE $4^{4,23,47}$ ). There is no evidence on which technique of moving a casualty is best.

\section{Recommendations (Grade D)}

As a general rule, do not move a casualty from the scene of the accident. Only move a casualty if he or she is in uncontrollable danger, and if it is safe for you to do so. In that case move the casualty to the nearest place of safety. Try to shield the casualty from cold or heat, but only move a casualty if he or she has been exposed to cold for a long time. Explain to a conscious casualty what you are going to do and ask for his or her cooperation. Use a technique that is safe for you and the casualty, is easily and quickly applied, without the need for special equipment. If possible, support the neck and avoid twisting the head, neck, and body during the procedure. 


\section{Initial evaluation and calling for help}

\section{Findings}

The recommendations below are based on a consensus of the Guideline Development Group as to what constitutes good practice.

\section{Recommendations (Grade D)}

Introduce yourself and explain what you are going to do. This will increase the casualty's confidence in you. Evaluate the casualty's condition. If help is needed, alert the EMS or local emergency response system, the Poison Control Centre (PCC) or other healthcare professionals as appropriate. Remember that 112 is the recognised emergency telephone number in all countries of the European Union. Always refer to healthcare professionals or social services if you have any suspicion of non-accidental injury.

\section{Psychosocial first aid}

\section{Findings}

The focus of the literature tends to be on the first weeks after an incident has occurred. Three guidelines on acute and post traumatic stress disorder, ${ }^{13,14,22}$ one systematic review on debriefing, ${ }^{48}$ and seven expert opinion scripts ${ }^{49-55}$ were selected. Single session debriefing or actively exploring emotions should not be done (LOE $1+,{ }^{14,48}$ LOE $4^{13,22,49,53}$ ); this has proven to be ineffective and potentially harmful. Single session debriefing is a psychological technique for a structured conversation about emotional and cognitive experiences. Laypersons providing initial psychosocial support need continuous training and assistance ( $\mathrm{LOE} 4^{51,54}$ ). Taking care of basic needs is part of psychosocial FA, but food or drink should not be given because this complicates professional care if anaesthesia is required.

\section{Recommendations (Grade D)}

Approach the casualty in a non-judgmental way. Listen empathetically to the casualty, be supportive, and offer practical assistance. Do not give food or drink to a sick or injured casualty, unless advised otherwise by professional healthcare providers. Explain carefully to the casualty what has happened and what is going to happen.

\section{Infection control}

\section{Findings}

We included three guidelines related to infection control. ${ }^{11,15,30}$ Cross-infection between first aider and casualty must be avoided. Hand hygiene, by using liquid soap and water, is an effective method of preventing cross-infection (LOE $1+,^{15}$ LOE $4^{30}$ ). The risk of cross-infection can be reduced by using a barrier (e.g. gloves) between the first aider and the blood or body fluids of the casualty (LOE $4^{11,15,30}$ ). Careful handling and disposal of glass, needles, or other sharp objects that might cut, graze, or prick is essential in preventing infection (LOE $4^{15,30}$ ).

\section{Recommendations (Grades B and D)}

Whenever possible, wash your hands with liquid soap and water before and after giving FA (B). Use disposable gloves if they are available (D); if not, a plastic bag may be used instead (D). Handle and dispose of sharp objects safely (D). If needles are present as a result of recreational drug use, then they should be identified and left to professionals to handle (D).

\section{Bleeding}

\section{Findings}

One guideline, 42 SRs on control of arterial puncture ${ }^{56}$ and on femoral vessel injuries in warfare, ${ }^{57} 2$ RCTs on control of arterial puncture, ${ }^{58,59} 11$ case reports or series, ${ }^{60-70}$ and 14 expert opinion scripts ${ }^{71-84}$ were selected. The effectiveness of controlling external bleeding through applying direct pressure or a compression bandage to the site of bleeding is proven by high level of evidence (LOE 1+, 4,56,58,59 LOE $3^{, 61,62,65,67,68}$ LOE $\left.4^{4,71-78,80-83}\right)$. There is insufficient evidence about the effectiveness of indirect pressure on pressure points and elevation (LOE 4,72,74-76,80-82). Because of the possible complications, the use of a tourniquet is contraindicated for laypersons (LOE 360,63-66,68-70, LOE 4 4, 57,72,75,76,79,80,82,84).

\section{Recommendations (Grades B and D)}

To control external bleeding, apply direct pressure or a compression bandage to the site of bleeding (B). If bleeding continues, apply more pressure or an additional bandage without removing the original dressing (D). Maintain pressure on the site of the 
wound until the EMS arrives (D). Do not use indirect pressure on pressure points and elevation, and do not use a tourniquet to control bleeding (D).

\section{Wounds}

\section{Findings}

Three guidelines on wound management $\mathrm{t}^{4,12,20}$ and one SR on water for wound cleansing ${ }^{85}$ were selected. Irrigating wounds with water reduces infection rates and improves healing rate (LOE $\left.1{ }^{85}\right)$. Irrigation should be continued until there appears to be no foreign matter left in the wound (LOE $\left.4^{4}\right)$. Swabbing the wound can damage the wound tissue $\left(\operatorname{LOE~} 4^{20}\right)$. There is debate amongst researchers as to whether the potential toxic effects of antiseptics and antibacterials on tissue may delay the healing of wounds; therefore, at present, use of antiseptics and antibacterials should be undertaken with caution (LOE $4^{12,20}$ ). Wound dressings are necessary to protect the wound $\left(\operatorname{LOE} 4^{20}\right)$. Tetanus immunisation is needed for all wounds. ${ }^{12}$ Many people do not know their exact immunisation status. One guideline included criteria for referral to healthcare professionals. ${ }^{12}$

\section{Recommendations (Grades B and D)}

After controlling bleeding, irrigate wounds with clean, running, cold, tap water if available (B); if not, use any source of drinkable water (B). Irrigate directly on the wound and continue until there appears to be no foreign matter left in the wound (D). Do not swab a wound (D). After cleaning a wound, cover it with sterile gauze if available (B); if not, use a clean dry cloth (D). Advise the casualty to seek medical advice to determine his/her tetanus immunisation status (D).

Do not remove an object that is embedded in a wound (D). Instead, try to immobilise it (D), then cover the wound with sterile gauze if available, or a clean dry cloth (D).

Referral to healthcare professionals is indicated if (D):

- an object is embedded in the wound;

- there is uncontrollable bleeding;

- an abrasion is larger than half the width of the palm of the casualty;

- bone, muscle, or other subcutaneous tissue is exposed;

- a wound involves the face, eyes, or genital area;

- a wound cannot be cleaned properly;

- a wound is caused by a bite.
Try to control bleeding until professional help is at hand.

\section{Burns}

\section{Findings}

We included six guidelines, 4,9,10,16,17,24 two case reports or series, ${ }^{86,87}$ one cross-sectional survey, ${ }^{88}$ and two expert opinion scripts ${ }^{89,90}$ on burns management. Burns should be cooled as soon as possible with tap-water (LOE $2++,{ }^{4}$ LOE $3,{ }^{86-88}$ LOE $\left.4^{9,16,24,90}\right)$. For some types of chemical burns, rinsing with water is potentially harmful (LOE $4^{9}$ ). The incidence of such burns, in a non-occupational setting, is low. This recommendation should, therefore, apply to both types of burn to allow uniform and simple guidelines for first aiders. The evidence for the optimum length of time a burn should be cooled is inconclusive (LOE $3^{87,88}$, LOE $4^{4,9,16,89}$ ). When cooling, hypothermia in the casualty must be prevented ( $\operatorname{LOE} 3{ }^{86-88} \operatorname{LOE} 4^{4,9,89}$ ). Clothing and jewellery can be removed, if they are not adhering to the skin (LOE 3, ${ }^{86,88} \operatorname{LOE} 4^{9,24,89,90}$ ). Intact burn blisters should not be opened (LOE $3,{ }^{4}$ LOE $4^{90}$ ). Antibiotic creams should not be used as FA. ${ }^{10}$ Wet wound dressings can protect the burn (LOE $3,^{88}$ LOE $4^{9,10,24,89,90}$ ). Tetanus immunisation is needed for burns. ${ }^{10,16}$ Many people do not know their exact immunisation status. Four guidelines (LOE $4^{10,16,17,24}$ ) included criteria for referral to healthcare professionals. The extent of a burn can be assessed with the Rule of Nines, the Lund and Browder chart, or with the palm of the casualty's hand (LOE $4^{10,16}$ ). The palm and fingers of the casualty's hand is approximately $1 \%$ of their total body surface area. There is no consensus in the research on the best method. The Rule of Nines should not be used for children under 16 years old. Using the casualty's hand is a feasible method for estimating the size of a burn at the scene.

\section{Recommendations (Grades B and D)}

Cool burns as soon as possible with tap-water (B). Continue cooling for $15-20 \mathrm{~min}$ or until pain relief is achieved or until professional help arrives (D). Prevent hypothermia in the casualty by avoiding use of very cold water for cooling, protecting casualties from the wind, and using blankets to keep the casualty warm (D). Remove clothing and jewellery if they are not adhering to the skin (D). After cooling, apply wet wound dressings (D). Do not open intact burn blisters (D). Advise the casualty to seek 
medical advice to determine his/her tetanus immunisation status (D).

Referral to healthcare professionals is indicated if (D):

- the casualty is a child under 5 years or an adult over 60 years;

- a burn involves face, ears, hands, feet, the genital area, or joints;

- there is a circumferential burn of the limbs, torso, or neck;

- there are burns covering more than $5 \%$ of total body surface area in children under 16 years, or more than $10 \%$ in adults over 16 years. The palm and fingers of the casualty's hand is approximately $1 \%$ of the total body surface area;

- there is a third-degree burn. If the deepest layer of the skin is burned, there is usually no pain in the wound itself, because the nerves in this area have also been destroyed. The burn can look black, parchment-like or white and is dry. However the skin around the wound, which is often less deeply burned, is painful;

- burns are electrical or chemical, or due to ionizing radiation, or high pressure steam;

- there is an inhalation burn.

\section{Spinal and head trauma}

\section{Findings}

One guideline on head trauma, ${ }^{21}$ one cohort study ${ }^{91}$ and one case series ${ }^{92}$ on spinal trauma were selected. Assessment of spinal or head trauma is difficult; in children this is even more difficult. All three studies provide criteria for referral to healthcare professionals (LOE $2++,{ }^{21,91}$ LOE $3^{92}$ ). There is no good evidence about when first aiders should expect head injury in children. There is no evidence that manual immobilisation in a non-moving victim is effective.

\section{Recommendations (Grades B and D)}

Initial evaluation of casualties who have an altered mental state, or who are intoxicated or in great pain is not very reliable. Alert the EMS if there is uncertainty about the nature of any injury (B).

Suspect head injury and alert the EMS if the casualty (B):

- is a victim of high-impact trauma such as from a traffic accident or a fall from higher than standing height;

- is or becomes drowsy, sleepy, agitated, or unconscious;
- does not remember precisely what has happened;

- has severe and persistent headache, nausea and vomiting, irritability, or altered behaviour, seizure;

- has major lesions to the head.

Suspect spinal injury and alert the EMS if the casualty (B):

- is a victim of high impact trauma such as from a traffic accident, or a fall from higher than standing height;

- is or becomes drowsy, sleepy, agitated, or unconscious;

- does not remember precisely what has happened;

- complains about numbness or tingling;

- is not complaining about serious injuries of the lower body or legs that would normally be expected to be painful;

- has pain or tenderness in the neck or back.

Calm a casualty with spinal or head trauma and try to convince him/her not to move (D). Only immobilise the casualty if he or she is cooperative (D). If the casualty is agitated, do not immobilise the head and neck against his/her will (D).

\section{Musculoskeletal trauma}

\section{Findings}

Four guidelines ${ }^{4,18,25,26}$ on musculoskeletal trauma and one $\mathrm{SR}^{93}$ about the use of ice in acute softtissue injury were selected. Initial evaluation of limb injuries is difficult. Evidence is inconclusive on the effectiveness of immediate post-injury cooling ( $\operatorname{LOE} 1+4,18,93$ ), and on the optimum duration of cooling (LOE $1+{ }^{93}$ ). No evidence was found about the effectiveness of elevation and compression. Avoiding standing on an injured lower limb (LOE $\left.4^{4}\right)$, or self immobilisation of an injured upper limb (LOE $\left.4^{25,26}\right)$, are often adequate and less painful than putting the limb in a bandage or a sling.

\section{Recommendations (Grade D)}

In case of doubt about the severity, assume that a fracture has occurred and refer to healthcare professionals. Do not try to reduce angulated or dislocated limbs. Cool the injury with ice. When cooling, use a barrier such as a towel between the ice and the skin and do not use for a prolonged time. Limit each period of cold application to a maximum of $20 \mathrm{~min}$. Do not immobilise the injured limb if medical help is available within a short time span. Advise the casualty not to stand on an injured 
lower limb. In case of upper limb injury, ask the casualty to immobilise the arm against the trunk himself/herself. If there is major bleeding at the fracture site, apply direct pressure or a compression bandage.

\section{Poisoning through oral ingestion}

\section{Findings}

Five guidelines $4,19,27-29$ and two expert opinion scripts ${ }^{94,95}$ were selected. Activated charcoal (LOE $4^{4,27,29,94}$ ), water, or milk (LOE $4^{4,94}$ ) should only be used if this is advised by a PCC or a professional healthcare provider. Ipecac syrup should not be used (LOE $1+,{ }^{4}$ LOE $3,{ }^{19}$ LOE $\left.427,28,28,94,95\right)$. We did not investigate whether body position has an effect on poison absorption. Future investigation is needed to test the hypothesis that left lateral decubitus decreases absorption.

\section{Recommendations (Grade D)}

Contact the PCC or professional healthcare providers and follow their instructions.

\section{Discussion}

There was limited evidence addressing FA. It was sometimes possible to extrapolate research findings on professional healthcare to FA; the 21 guidelines retrieved were very useful for this purpose. When evidence was available, we were able to turn science into practice. When evidence was not available, our recommendations are consensusbased. Effective and appropriate FA procedures and techniques have been described, and interventions that are contraindicated have been identified. Even though the evidence base was limited, these guidelines provide systematically developed recommendations and justifications for the procedures and techniques that should be included in FA manuals and training programmes.

Customary practices are not always correct. If research shows that first aid can become better, one should not be blind to that fact. It is strongly advised that FA manuals and programmes be reviewed in the light of these guidelines and revised where appropriate. The European Reference Guide for FA Instruction and EFAM are handy tools to update or develop teaching material and can be requested at the website http://www.efam.be.
Until now, there has been no explicit description of the status of research on FA. This study illustrates the need for more research which is necessary to ensure the quality of FA provision. Specifically, research is required on how well first aiders can perform immobilisation techniques, and on the optimum duration of irrigation for burns and cooling after musculoskeletal trauma.

We hope these guidelines will encourage the scientific community to start new research efforts in FA. As new evidence becomes available, these guidelines will need to be revised. A strategy must be developed to bring in wider European representation and to include additional basic and advanced FA topics when these guidelines are updated.

\section{Contributors}

The Belgian Red Cross-Flanders is very grateful for the work that has been done by the participating experts. S. Van de Velde, (Belgian Red CrossFlanders) planned, coordinated, facilitated and drafted the study report. P. Broos (University Hospital Gasthuisberg Leuven, Belgium) supervised the study and chaired the expert group. B. Aertgeerts (Belgian Centre for Evidence-Based Medicine) gave methodological advice. The systematic literature review was done by: R. De Win (Belgian Red CrossFlanders), D. Lauwaert (Academic Hospital Free University Brussels, Belgium), A. Sermon (University Hospital Gasthuisberg Leuven, Belgium), C. Tobback (Poison Control Centre Belgium), M. Van Bouwelen (Belgian Red Cross-Flanders), P. Van den Steene (Stressteam Federal Police Belgium), A. van Tichelen (Saint-Marie Hospital Halle, Belgium), B. Vantroyen (University Hospital Gasthuisberg Leuven, Belgium), J. Verduyckt (University Hospital Gasthuisberg Leuven, Belgium). Advisors on specialist topics were: J. Bierens (VU University Medical Centre Amsterdam, Netherlands), P. Broos, P. Cassan (European Reference Centre for First Aid Education, France), E. Davoli (World Health Organisation), M. De Vries (Impact Foundation, Dutch Knowledge Centre for Post-Disaster Psychosocial Care), G. Göbl (Hungarian Red Cross), G. Lo (International Federation of the Red Cross and Red Crescent Societies, IFRC), C. Urkia Mieres (Spanish Red Cross), K. Monsieurs (European Resuscitation Council), M. Sabbe (University Hospital Gasthuisberg Leuven, Belgium), S. Schunder (Austrian Red Cross), and S. Villere (Latvian Red Cross). External validators were D. Ramaekers (Belgian Health Care Knowledge Centre), H. Van Brabant (Belgian Health Care Knowledge Centre) and P. Vranckx (Virga Jesse Hospital Hasselt, Belgium). 


\section{Conflict of interest statement}

The Red Cross provides training in first aid.

\section{Acknowledgements}

We are grateful to the IFRC for their permission to cite from the First recommendations on life-saving techniques report. ${ }^{11}$ We thank A. Handley (Colchester, UK) for reviewing and editing the manuscript.

Funding: The European Commission funded this study. The Commission did not participate in the guideline development process and is not responsible for any use that may be made of the information in this publication.

\section{References}

1. Mauritz W, Pelinka LE, Kaff A, Segall B, Fridrich P. First aid measures by bystanders at the place of accident. A prospective, epidemiologic study in the Vienna area. Wien Klin Wochenschr 2003;115:698-704.

2. Larsson EM, Martensson NL, Alexanderson KA. First-aid training and bystander actions at traffic crashes-a population study. Prehospital Disaster Med 2002;17:134-41.

3. Abernethy L, MacAuley D, McNally 0 , McCann S. Immediate care of school sport injury. Inj Prev 2003;9:270-3.

4. American Heart Association Guidelines for Cardiopulmonary Resuscitation and Emergency Cardiovascular Care. Circulation 2005;112:IV1-IV203.

5. Handley AJ, Koster R, Monsieurs K, Perkins GD, Davies $\mathrm{S}$, Bossaert L. European Resuscitation Council guidelines for resuscitation 2005. Section 2. Adult basic life support and use of automated external defibrillators. Resuscitation 2005;67:S7-S23.

6. Scottish Intercollegiate Guidelines Network. SIGN 50: A guideline developer's handbook. Edinburgh: SIGN; 2004. Available from: http://www.sign.ac.uk/guidelines.

7. Atkins $D$, et al. Systems for grading the quality of evidence and the strength of recommendations. I. Critical appraisal of existing approaches. BMC Health Serv Res 2004;4:38.

8. The AGREE Collaboration. Appraisal of Guidelines for Research \& Evaluation (AGREE) Instrument. The AGREE Collaboration; 2001. Available from: http: / /www. agreecollaboration.org.

9. Allison K, Porter K. Consensus on the prehospital approach to burns patient management. Emerg Med J 2004;21(1):112-4.

10. Sowerby Centre for Health Informatics at Newcastle (SCHIN). Prodigy Guidance: burns and scalds. Prodigy Guidance; 2004. Available from: http://www.prodigy.nhs.uk.

11. International harmonization of First Aid. First recommendations on life-saving techniques. International Federation of Red Cross and Red Crescent Societies; 2004.

12. Sowerby Centre for Health Informatics at Newcastle (SCHIN). Prodigy Guidance: lacerations. Prodigy Guidance; 2004. Available from: http://www.prodigy.nhs.uk.

13. Ursano RJ, Bell C, Eth $S$, et al. Practice guideline for the treatment of patients with acute stress disorder and post traumatic stress disorder. Am J Psychiatry 2004;161:3-31.

14. National Collaborating Centre for Mental Health. Post traumatic stress disorder: the management of PTSD in adults and children in primary and secondary care. London (UK): National Institute for Clinical Excellence (NICE); 2005. Available from: http://www.guideline.gov.

15. National Collaborating Centre for Nursing, Supportive Care. Infection control. Prevention of healthcare-associated infection in primary and community care. London (UK): National Institute for Clinical Excellence (NICE); 2003. Available from: http://www.nice.org.uk.

16. American Burn Association. Practice guidelines for burn care. J Burn Care Rehabil 2001;22:19s-26s.

17. National Burn Care Review Committee. National burn care review. British Association of Plastic Surgeons; 2001. Available from: http://www.baps.co.uk.

18. van Dijk CN. CBO-guideline for diagnosis and treatment of the acute ankle injury. National organization for quality assurance in hospitals. Ned Tijdschr Geneeskd 1999;143:2097-101.

19. Manoguerra AS, Cobaugh DJ. Guideline on the use of ipecac syrup in the out-of-hospital management of ingested poisons. Clin Toxicol 2005;43:1-10.

20. Crest. Guidelines on the general principles of caring for patients with wounds. Belfast: Clinical Resource Efficiency Support Team; 1998. Available from: http://www. crestni.org.uk.

21. Scottish Intercollegiate Guidelines Network. SIGN 46: Early management of patients with a head injury. Edinburgh: SIGN; 2000. Available from: http://www.sign.ac.uk/guidelines.

22. Gray MJ, Litz BT. Behavioral interventions for recent trauma: empirically informed practice guidelines. Behav Modif 2005;29:189-215.

23. Joint Royal Colleges Ambulance Liaison Committee (JRCALC). Street safety. Emergency Care Specialist Library, Joint Royal Colleges Ambulance Liaison Committee; 2004. Available from: http://www.library.nhs.uk/emergency.

24. Joint Royal Colleges Ambulance Liaison Committee (JRCALC). Burns. Emergency Care Specialist Library, Joint Royal Colleges Ambulance Liaison Committee; 2004. Available from: http://www.library.nhs.uk/emergency.

25. Joint Royal Colleges Ambulance Liaison Committee (JRCALC). Limb trauma. Emergency Care Specialist Library, Joint Royal Colleges Ambulance Liaison Committee; 2004. Available from: http://www.library.nhs.uk/emergency.

26. Joint Royal Colleges Ambulance Liaison Committee (JRCALC). Splintage. Emergency Care Specialist Library, Joint Royal Colleges Ambulance Liaison Committee; 2004. Available from: http://www.library.nhs.uk/emergency.

27. American Academy of Pediatrics Committee on Injury, Violence, Poison Prevention. Poison treatment in the home. Pediatrics 2003;112:1182-5.

28. American Academy of Clinical Toxicology, European Association of Poisons Centres and Clinical Toxicologists. Position paper: Ipecac syrup. J Toxicol Clin Toxicol 2004;42:133-43.

29. Chyka PA, Seger D, Krenzelok EP, Vale JA. Position paper: single-dose activated charcoal. Clin Toxicol 2005;43:6187.

30. Joint Royal Colleges Ambulance Liaison Committee (JRCALC). Infection control. Emergency Care Specialist Library, Joint Royal Colleges Ambulance Liaison Committee; 2004. Available from: http://www.library.nhs.uk/ emergency.

31. Coats TJ, Davies G. Prehospital care for road traffic casualties. Br Med J 2002;324:1135-8.

32. Meade DM, Dernocoeur K. Principles of emergency vehicle placement. Emerg Med Serv 1998;27:34-5.

33. Czajkowski J, Kidd S. Extrication challenges. 10 tips for EMS crews working at extrication scenes. EMS on scene. JEMS 2001;26:50-61. 
34. Meola JJ. Fresh ideas for keeping crews safe. Occup Health Saf 2000;69(38-42):44.

35. Methner P. Extrication scene tips for EMS personnel: EMS considerations to enhance scene operations and personal safety. JEMS 2004;29:28-35.

36. Moore JE, Giuliano G, Cho S. Secondary accident rates on Los Angeles freeways. J Transport Eng ASCE 2004;130:280-5.

37. Platt WD. Behaviour at the scene of an accident. Br J Nurs 1992;1:678-80.

38. Stack JK. Immediate measures at site of accident. J Trauma 1966;6:285-98.

39. Jaslow D, Ufberg J, Yoon R, McQueen C, Zecher D, Jakubowski G. Fire safety knowledge and practices of the elderly. Emerg Med Serv 2004;33:111-5.

40. Chamberlain A. First aid in chemical environments. Chem $\mathrm{Br}$ 1983;19:318-23.

41. First aid series. Electrocution. Nurs Times 1999;95:49.

42. Clave $M$. Accidents due to electricity. Rev Infirm 1980;30:33-9.

43. Erskine JF. Electrical accidents. Practitioner 1979;222: 777-81.

44. Lederer W, Wiedermann FJ, Cerchiari E, Baubin MA. Electricity-associated injuries. I. Outdoor management of current-induced casualties. Resuscitation 1999;43:69-77.

45. Pedersen EB. Safety at disaster sites. Aust Fam Physician 1978;7, 25-7, 29.

46. Zorn H. First aid in electric injuries. Zentralbl Arbeitsmed Arbeitsschutz Prophyl 1976;26:180-8.

47. Doering JJ. Emergency lift for the immobile elderly. Can Nurse 2002;98:31-5.

48. Rose S, Bisson J, Churchill R, Wessely S. Psychological debriefing for preventing post traumatic stress disorder (PTSD). Cochrane Database Syst Rev 2005.

49. Bryant RA. Psychosocial approaches of acute stress reactions. CNS Spectr 2005;10:116-22.

50. Kutz I, Bleich A. Mental health interventions in a general hospital following terrorist attacks: the Israeli experience. J Aggr Maltreat Trauma 2005;10:425-37.

51. Pardess E. Training and mobilizing volunteers for emergency response and long-term support. J Aggr Maltreat Trauma 2005;10:609-20.

52. Resnick H, Acierno R, Kilpatrick DG, Holmes M. Description of an early intervention to prevent substance abuse and psychopathology in recent rape victims. Behav Modif 2005;29:156-88.

53. Schnyder U. Psychotherapies for PTSD-an overview. Psychotherapies 2005;25:39-52.

54. Van Ommeren M, Saxena S, Saraceno B. Mental and social health during and after acute emergencies: emerging consensus? Bull World Health Org 2005;83:71-5.

55. Watson PJ, Shalev AY. Assessment and treatment of adult acute responses to traumatic stress following mass traumatic events. CNS Spectr 2005;10:123-31.

56. Koreny M, Riedmuller E, Nikfardjam M, Siostrzonek P, Mullner M. Arterial puncture closing devices compared with standard manual compression after cardiac catheterization: systematic review and meta-analysis. JAMA 2004;291:350-7.

57. Pearl JP, MCNally MP, Perdue PW. Femoral vessel injuries in modern warfare since Vietnam. Military Med 2003;168:733-5.

58. Lehmann KG, Heath-Lange SJ, Ferris ST. Randomized comparison of hemostasis techniques after invasive cardiovascular procedures. Am Heart J 1999;138:1118-25.

59. Walker SB, Cleary S, Higgins M. Comparison of the FemoStop device and manual pressure in reducing groin puncture site complications following coronary angioplasty and coronary stent placement. Int J Nurs Pract 2001;7:366-75.
60. Lakstein D, Blumenfeld A, Sokolov T, et al. Tourniquets for hemorrhage control on the battlefield: a 4-year accumulated experience. J Trauma Injury Infect Crit Care 2003;54:S221-5.

61. Naimer SA, Nash M, Niv A, Lapid O. Control of massive bleeding from facial gunshot wound with a compact elastic adhesive compression dressing. Am J Emerg Med 2004;22:586-8.

62. Gadzhiev NA, Kosenkov AN. Organization of treating patients with major vessel injuries at stages of evacuation. Khirurgiia 2003;6:22-7.

63. Pilcher DB, Gettinger Jr CE, Seligson D. Recurrent themes in ambulance critique review sessions over eight years. $J$ Trauma 1979;195:324-8.

64. Bouma S. First aid in hemorrhages, the use of tourniquets Ned Tijdschr Geneeskd 1966;110:1255-7.

65. Dorlac WC, DeBakey ME, Holcomb JB, et al. Mortality from isolated civilian penetrating extremity injury. J Trauma Injury Infect Crit Care 2005;59:217-22.

66. Calkins D, Snow C, Costello M, Bentley TB. Evaluation of possible battlefield tourniquet systems for the far-forward setting. Military Med 2000;165:379-84.

67. Pohlemann T, Paul C, Gansslen A, Regel G, Tscherne H. Traumatic hemipelvectomy. Experiences with 11 cases. Unfallchirurg 1996;99:304-12.

68. Fasol R, Irvine S, Zilla P. Vascular injuries caused by antipersonnel mines. J Cardiovasc Surg 1989;30:467-72.

69. Kornbluth ID, Freedman MK, Sher L, Frederick RW. Femoral, saphenous nerve palsy after tourniquet use: a case report. Arch Phys Med Rehabil 2003;84:909-11.

70. Savvidis E, Parsch K. Prolonged transitory paralysis after pneumatic tourniquet use on the upper arm. Unfallchirurg 1999;102:141-4.

71. Beck A, Gebhard F, Kinzl L, Strecker W. Principles and techniques of accident surgery primary care at the accident site. Unfallchirurg 2001;104:1082-99.

72. Boericke $\mathrm{PH}$, Boericke $\mathrm{CH}$. Emergency! Part 2. First aid for open wounds, severe bleeding, shock, and closed wounds. Nursing 1975;5:40-6.

73. Broos PL, Willaert WI. Notorious pitfalls in the care of multitrauma patients. Acta Chir Belg 2003;103:346-54.

74. Clifford CC. Treating traumatic bleeding in a combat setting. Mil Med 2004;169(8-10):4.

75. Donelan S. Teaching wound care and bandaging: an historical perspective. Wilderness Environ Med 2003;14:47-56.

76. Dunant JH. Emergency treatment of hemorrhage. Ther Umsch 1979;36:1059-61.

77. Garner JP, Brown RFR. Recent advances in topical agents for prehospital haemostasis. Trauma 2002;4:203-9.

78. Holcomb JB. Methods for improved hemorrhage control. Crit Care 2004;8:S57-60.

79. Husum H, Gilbert M, Wisborg T, Pillgram-Larsen J. Prehospital tourniquets: there should be no controversy. J Trauma Injury Infect Crit Care 2004;56:214-5.

80. Jacobs LM. Initial management and evaluation of the multisystem injured patient, Part 1. J Natl Med Assoc 1987;79:361-70.

81. Kunin IJ. Principles of first aid. Dent Clin North Am 1965:789-801.

82. London PS. Treatment of soft tissue injuries at the roadside. Br Med J 1969;4:284-6.

83. Muhr G, Tscherne H. Rescue and first aid for the severely traumatized. Chirurg 1978;49:593-600.

84. Navein J, Coupland R, Dunn R. The tourniquet controversy. J Trauma 2003;54:S219-20.

85. Fernandez R, Griffiths R, Ussia C. Water for wound cleansing. Cochrane Database Syst Rev 2005. 
86. Jester I, Jester A, Demirakca S, Waag KL. Pre-hospital emergency management in pediatric burns. Intensivmedizin und Notfallmedizin 2005;42:60-5.

87. O’Neill AC, Purcell E, Jones D, Pasha N, McCann J, Regan P. Inadequacies in the first aid management of burns presenting to plastic surgery services. Ir Med J 2005;98:15-6.

88. Walker A, Baumber R, Robson B. Pre-hospital management of burns by the UK fire service. Emerg Med J 2005;22:205-8.

89. Hudspith J, Rayatt S. ABC of burns: first aid and treatment of minor burns. Br Med J 2004;328:1487-9.

90. Morgan ED, Bledsoe SC, Barker J. Ambulatory management of burns. Am Fam Physician 2000;62:2015-26.

91. Dunn TM, Dalton A, Dorfman T, Dunn WW. Are emergency medical technician-basics able to use a selective immobi- lization of the cervical spine protocol? A preliminary report. Prehosp Emerg Care 2004;8:207-11.

92. Domeier RM, Frederiksen SM, Welch K. Prospective performance assessment of an out-of-hospital protocol for selective spine immobilization using clinical spine clearance criteria. Ann Emerg Med 2005;46:123-31.

93. Bleakley C, McDonough S, MacAuley D. The use of ice in the treatment of acute soft-tissue injury: a systematic review of randomized controlled trials. Am J Sports Med 2004;32:251-61.

94. Bailey B. Gastrointestinal decontamination triangle [2]. J Toxicol Clin Toxicol 2005;43:59-60.

95. Krenzelok EP. Ipecac syrup-induced emesis ... no evidence of benefit. Clin Toxicol 2005;43:11-2. 